\title{
Managerial Allocation of Time and Effort: The Effects of Interruptions
}

\author{
Sridhar Seshadri • Zur Shapira \\ Leonard N. Stern School of Business, New York University, 44 W. 4th Street, 7-60, New York, New York 10012-1126 \\ sseshadr@stern.nyu.edu・zshapira@stern.nyu.edu
}

\begin{abstract}
$\mathrm{T}$ ime is one of the more salient constraints on managerial behavior. This constraint may be very taxing in high-velocity environments where managers have to attend to many tasks simultaneously. Earlier work by Radner (1976) proposed models based on notions of the thermostat or "putting out fires" to guide managerial time and effort allocation among tasks. We link these ideas to the issue of the level of complexity of the tasks to be attended to while alluding to the sequential versus parallel modes of processing. We develop a stochastic model to analyze the behavior of a manager who has to attend to a few short-term processes while attempting to devote as much time as possible to the pursuit of a long-term project. A major aspect of this problem is how the manager deals with interruptions. Different rules of attention allocation are proposed, and their implications to managerial behavior are discussed. (Attention; Decision Rules; Priority Setting; Satisficing; Thermostat; Controlled Markov Process)
\end{abstract}

\section{Introduction}

In a landmark study of managerial work, Mintzberg (1973) described the way managers behave. He observed that managers work at an unrelenting pace on a large number of tasks subject to frequent interruption. In summarizing his findings, Mintzberg argued,

\begin{abstract}
The manager, particularly at senior levels, is overburdened with work. With the increased complexity of modern organizations and their problems he is destined to become more so. He is driven to brevity, fragmentation, and superficiality in his tasks, yet he cannot easily delegate them because of the nature of his information. And he can do little to increase his available time or significantly enhance his power to manage. Furthermore, he is driven to focus on what is current and tangible in his work (1973, p. 173).
\end{abstract}

In the 28 years since the publication of Mintzberg's book, many changes have occurred in managerial work as a result of the rapid progress of information technology. Data that required substantial effort to acquire 28 years ago is at the fingertips of managers. Sophisticated analyses and forecasting packages allow executives to examine multiple perspectives on deci- sion problems instantaneously. Interactive digital technology, in the form of the Internet and corporate intranets, give individuals at all levels of organizations access to vast amounts of information, and the volume of electronic mail can overload almost every individual. Yet, while information technology has had a substantial impact on the nature of managerial work, the time constraints managers face may have become even more prohibitive.

Time as a scarce resource has been examined by economists (e.g., Ghez and Becker 1975) who treat the allocation of time as a rational decision. Management researchers are cognizant of the notion of bounded rationality, which is interpreted as an inherent constraint on one's ability to process information. Bounded rationality coupled with time constraints may lead to serious difficulties, especially if one considers managerial decision making in high-velocity environments (Eisenhardt 1989). Time pressure leads to changes in strategies employed by decision makers such as the overweighting of negative cues (Wright 1974, see also Maule and Svenson 1993). 
Other researchers examined the effect of time constraints on performance in organizational settings. Lin and Carley (1997) argue that organizational performance has been approached from two perspectives: The organization theory perspective emphasizes the relations between an organization and its environment, while the information-processing paradigm focuses on the role that intelligent agents play in making decisions in dynamic environments. Following the latter, Lin and Carley examined the effect of time constraints on organizational decision making using a simulation of decisions regarding a moving aircraft. They demonstrate that time pressure affects performance negatively. At the individual level of analysis, Ye and Carley (1995) demonstrate how one can explain organizational behavior at the macro-level based on analysis of individual decision making using the Radar-Soar framework.

Recently researchers have started to pay more attention to the effect of interruptions on individual performance. For instance, Speier et al. (1999) showed in an experimental setting that interruptions undermine performance on complex decision tasks but improve decision making on simple tasks. Sarason et al. (1996) assembled research addressing the effects of cognitive interference on a variety of aspects of human behavior, such as information processing, stress, and performance. Perlow (1999) conducted a field study to examine the ways software engineers use their time at work and found that interruptions had a major effect on performance.

The present paper also focuses on interruptions but differs from the above work in some respects. We take for granted that time constraints are present in a manager's job and that time pressure may lead to errors, but we do not focus on errors. We consider a manager who realizes that he has to deal with conficting demands on his time and attention, and we analyze priority setting mechanisms that can help him deal with these conflicting demands. We assume that a manager has an array of rules available to him to deal with such a problem, and we point at the "most appropriate" rule in a given context. In so doing, we extend Radner's (1976) notion of "putting out fires," meaning that managers allocate their attention only to those projects or issues that they perceive as pressing problems. For example, managers may put out fires by dealing with the biggest problems first and then attending to the next "fire." Radner also used the notion of a thermostat to describe how problems capture the attention of managers. Both notions, putting our fires and the thermostat model, suggest that managers are focusing on issues and problems in an attempt to meet some minimally acceptable levels of performance that are deemed sufficient or "good enough," that is, satisficing (Simon 1955).

The putting out fires metaphor describes only part of the picture. Managers have to deal with short-term pressing problems, but they often have a less immediate long-term goal such as dealing with an innovative R\&D project at a high level of complexity. The manager would like to devote all her attention to this particular project, yet she has to monitor work on other "short-term" projects in a "maintenance" mode. That is, the manager needs to make sure that work on these short-term projects continues and doesn't fall below a particular level. If performance on these short-term projects is above a certain level, the manager can allocate her attention to the long-term project. The idea of different goals draws on March and Shapira's (1992) notion of attention to targets as affecting managerial risk-taking. In their model, managers are motivated by two goals: assuring survival and attempting to reach a certain aspiration level. Managerial risk taking is affected by the manager's asset position vis-à-vis these two targets and the target on which she focuses. Similarly, a manager in our model focuses either on an acceptable level of a short-term process or on its minimally acceptable level and directs her attention accordingly.

To deal effectively with multiple tasks and goals, managers need to develop ways of setting priorities. A naive model of managerial behavior may assume that managers are capable of monitoring many projects simultaneously. This idea of managers as parallel distributed information-processing systems is appealing but may be limited in its applicability. As Simon (1992) noted, the question whether information processing is done in a serial or a parallel distributed manner depends on the complexity level of the problem being processed. If "higher" level 
nonautomatic functioning is required, attention may need to be focused on some small part of the problem, leading to a serial form of processing, hence the need for priority setting. Operating within time constraints further aggravates the problem, that is, the inability to monitor many projects simultaneously requires priority setting. Further, working on the long-term project that is of a high-level of complexity mandates a serial processing model (at least when work on this project is concerned).

Managerial decision making has been compared, at times, to the way grand masters play chess (Simon 1987). It is clear that grand masters may simultaneously play many players of a lower-level of expertise; however, they do not play simultaneous games against players of their own level. In developing our model we follow Simon's $(1967,1992)$ basic notion that dealing effectively with multiple tasks of which at least one is of a high-level of complexity should be sequential in the part dealing with that task. Setting priority order among tasks may seem to be at odds with descriptive accounts of managerial work (cf. Mintzberg 1973) because managers get interrupted frequently. It is indeed this very aspect that makes the need to set priorities even more important because interruptions are costly in that, getting started on an interrupted task requires set-up time. A manager may need to "go back" a bit to recover her thinking process on that project.

This "going back" phenomenon has a cost associated with it, at least in that there is time needed to recover the earlier thinking position. If the problem the manager is working on requires some creativity, the cost may be high and the loss of the prior thinking position may be irreversible. Because managers expect to be interrupted, setting a rigid priority order system may not be efficient and at times may not work at all. Thus, the priority order should be flexible and allow the manager to shift back and forth among projects. In addition, we assume that managers in organizational settings need to deal with multiple projects, hence the possibility that the manager may drop all activities and focus on only one project whose "expected return" dominates the other projects is ruled out. Such a model may describe the behavior of an entrepreneur but not the behavior of most managers who work in a hierarchical organization.

In modeling these ideas we look at different rules of priority setting. We follow Simon's notion of thermostat and Radner's notion of putting out fires. In addition, we discuss a multitude of other rules suggested by Levitt et al. (1994). They observed the communication behavior of design teams and noted that managers use a "variety of rules in dealing with messages, such as setting priorities, following last in-first out (LIFO) or first in-first out (FIFO), as well as random rules. We discuss these rules in detail in $\$ 4$.

In the next section we present a simple model that is built on the premise that the manager devotes time to two types of activities: maintenance and a developmental activities. Maintenance activities interrupt development work. They comprise attending to one or more so called "short-term-oriented" processes that deteriorate if attention is not paid to them. The developmental activity consists of attending to a "long-term-oriented" project so as to improve its performance. The performance of each process is characterized by a corresponding number called the level. The higher the level, the better the performance. The goals of the manager are to maintain the shortterm-oriented processes above their respective acceptable levels of performance, while striving to increase the level of the long-term process at an acceptable rate of improvement called the long-term goal. The acceptable levels for the short-term processes are critical values in the sense that by not immediately attending to at least one of the short-term processes requiring attention, the manager risks failure. Therefore, if the level of a short-term process falls below its acceptable value, the manager is interrupted from whatever work is at hand and has to attend immediately to the maintenance activity if no other short-term process is below its acceptable level. If more than one shortterm process is below the acceptable level, then the manager has to use a system of priorities for dealing with the situation. The manager is assumed to use rules and not necessarily optimum-seeking methods in deciding which process to attend to, when to attend to a process, and for how long. According to the model, the manager's choice of rule is successful 
if both goals are met, that is, maintaining all shortterm processes above the lower threshold level (called stability) and improving the long-term process at an acceptable rate. In the first model, we assume that interruptions are costless, that is, there is no cost associated with switching attention from one process to another. We derive conditions that are both necessary, as well as sufficient, for the manager to be successful in this environment. These conditions state that the fraction of time available to the manager after attending to all maintenance (short-term activities) should be at least equal to the fraction of time necessary to prevent the deterioration of the long-term process and the fraction needed to improve it at the desired rate.

In the second model, we introduce a cost associated with switching from the long- to the short-term process. We consider three issues to be important for the manager's success: the stability of the short-term processes, the growth rate of the long-term process, and the variance of the time available to attend to the long-term process. The first two criteria of success remain the same as in the costless environment. The third criterion for success is predicated on the assumption that the lower the variance of the time available to work on the long-term project, the more fruitful the work of the manager on the long-term project. Variance is also important if the marginal progress made by the manager when working on the long-term project at any one sitting decreases as a function of the time spent (in other words, the progress made in any one sitting is an increasing and concave function of time spent). Thus, very long spells might be inefficient. On the other hand, high variance implies that there would be some periods in which the time available to work on the long-term process may be too short to even recover the earlier thinking position (before being interrupted). We derive conditions that are both necessary and sufficient for the manager to be successful in this "costly interruptions" type environment. The conditions for success in the two environments, costless and costly, are outwardly similar, but there is a key difference. When interruptions are costly, the variance of the time available to the manager to attend to the long-term process is significantly affected by the choice of rule. The implications of this finding are discussed in the last section.

\section{When Interruptions Are Costless}

Time is discrete in this model. There are $n$ "shortterm"-oriented processes. Process 0 (zero) is "longterm" oriented. The performance of process $i$ is represented by the level $L_{i}(t)$ at time $t$. The level $L_{i}(t)$ can assume only integer values, i.e., values in $\{\ldots,-2,-1,0,1,2, \ldots\}$. The manager attends to only one process in any given time period. The level of process $i$ when unattended either remains the same with probability $\left(1-d_{i}\right)$ or else decreases by one level with probability $d_{i}$. Therefore, process $i$ when unattended deteriorates at an average rate of $d_{i}$ per time unit. When the manager devotes attention to process $i$, its level either remains the same with probability $\left(1-u_{i}\right)$, or else it increases by one level with probability $u_{i}$. Thus, process $i$ when attended to improves at an average rate of $u_{i}$ per time unit. We adopt the convention of taking the critical level for all short-term processes to be the same and equal to 0 . In practice, the critical level for each process could be arbitrary but fixed. The convention we adopt does not alter the results as long as the critical levels remain fixed. The manager uses certain rules to attend to the $(n+1)$ processes.

We require the following quantities to describe the evolution of the processes over time as well as to define what is meant by rules. Consider an interval of time $[0, t]$. Let $A_{i}(t)$ be 1 or 0 according to whether the manager does or does not attend to process $i$ in period $t$. In each period the manager attends to exactly one of the processes. For each $i=0,1,2, \ldots, n$, let $U_{i}(t)$ be a sequence of independent and identically distributed (i.i.d.) random variables with $\operatorname{Pr}\left[U_{i}(t)=1\right]=$ $u_{i}, \operatorname{Pr}\left[U_{i}(t)=0\right]=1-u_{i}$. Let, $D_{i}(t)$ be a sequence of i.i.d. random variables with $\operatorname{Pr}\left[D_{i}(t)=1\right]=d_{i}$, $\operatorname{Pr}\left[D_{i}(t)=0\right]=1-d_{i}$, and assume that the $2(n+1)$ processes $\left\{U_{i}(t)\right\}$ and $\left\{D_{i}(t)\right\}$ are mutually independent. Then, the evolution of the processes can be described by the equation

$$
\begin{array}{r}
L_{i}(t)=L_{i}(t-1)+A_{i}(t) U_{i}(t)-\left[1-A_{i}(t)\right] D_{i}(t), \\
i=0,1,2, \ldots, n .
\end{array}
$$

Let $H(t)$ denote the history of all the process levels from period 0 through period $t$, and let

$$
A(t) \equiv\left[A_{0}(t), A_{1}(t), \ldots, A_{n}(t)\right]
$$


denote the action taken by the manager in period $t$. The set of possible actions in any one period is

$$
\widetilde{A} \equiv\left\{\left(a_{0}, a_{1}, \ldots, a_{n}\right): a_{i}=1 \text { or } 0 ; \quad \sum_{i=0}^{n} a_{i}=1\right\} .
$$

In each period $t$, the manager chooses $\mathrm{A}(t)$ as a function of the history $H(t-1)$. A rule or strategy for the manager is a sequence $\sigma=\{\sigma(t)\}$ of mappings $\sigma(t)$ from the set of histories $H(t-1)$ to the set $\tilde{\mathrm{A}}$ of actions. To use such a rule the manager must have access to the states of the processes at time $(t-1)$. This might not be the case, for instance, if there is either delay in obtaining information or if the information is not perfect. Both of these cases are worth investigating but are beyond the scope of this paper. Let $N_{U}^{i}(t)$ be the number of time intervals during which process $i$ was attended to during $[0, t]$, i.e.,

$$
N_{U}^{i}(t)=\sum_{s=0}^{t} \mathrm{~A}_{i}(\mathrm{~s})
$$

Define $N_{D}^{i}(t)$ as the number of time intervals, each of unit length, during which process $i$ was unattended in $[0, t]$, i.e.,

$$
N_{D}^{i}(t)=\sum_{s=0}^{t}\left(1-\mathrm{A}_{i}(\mathrm{~s})\right)
$$

In this notation the subscripts $U$ and $D$ stand for up and down, respectively. Then, by definition,

$$
N_{U}^{i}(t)+N_{D}^{i}(t)=\sum_{s=0}^{t} A_{i}(s)+\sum_{s=0}^{t}\left(1-A_{i}(s)\right)=t .
$$

We now define the notion of success achievement more precisely, using Equation (2). To this end we introduce the concept of stability. Because of the stochastic nature of these processes, it might be virtually impossible (except by the use of complex rules as discussed below and in §4) to guarantee that their levels remain always above the critical level. On the other hand, a manager might like to assert that these processes are under control. Such an assertion implies that their levels are never negatively infinite; if any one level became negatively infinite, then no amount of effort exerted by the manager can restore the process to a level above 0 . Therefore, the minimal reassurance the manager might require to assert that the short-term processes are under control is that there exists a rule such that starting at any time, and by the use of this rule it is possible to drive the levels of all short-term processes above 0 . We define this "minimal" condition as stability and make it precise as follows: Assume that the manager follows a given rule, say $r$. Let $t$ be greater than or equal to 0 . Let $T_{r}(t)$ be the time required, under rule $r$, to restore the levels of all short-term processes to values greater than 0 (i.e., $T_{r}(t)=\inf \left\{t: L_{i}(t+t)>0\right.$ for $\left.i=1,2, \ldots, n\right\}$ ). Then rule $r$ achieves stability if there exists a constant $M$ such that for any $t$ greater than 0 ,

$$
E\left[T_{r}(t)\right] \leq M .
$$

Equation (3) means that viewed from any point in time (say $t_{0}$ ) the levels of all short-term processes will eventually exceed 0 . It is important to note that the condition in (3) will prevent any "slow" drift to $-\infty$. This definition is borrowed from Buzacott and Shanthikumar (1993). Our approach differs from that of Radner (1975), Radner and Rothschild (1975), and Rothschild (1975) in this regard. In their approach, the notion of "being in control" is captured by either one of two statements: The probability that none of the short-term processes ever falls to 0 is positive, or the levels of the short-term processes grow infinitely large. Their definition is motivated by the idea that the manager attempts to "survive" by attempting to keep the levels of the short-term processes from ever dropping below the critical level, and the manager "eventually succeeds" if the levels of the short-term processes grow infinitely large.

Stability is a well-defined concept in the queueing literature, see, for example, Cohen (1969). The use of this concept in the present context is appropriate because we could, if we choose, represent the manager as a (very flexible) server who attends to the work of maintaining and improving a system. We seek conditions that are necessary and sufficient to guarantee the stability of the short-term processes. Surprisingly, when these conditions are met, we prove that the manager can contrive to improve the shortterm processes at a very slow rate and, thus, prevent them from ever becoming critical (i.e., the manager "survives" and "eventually succeeds" in the definitions of Radner and Rothschild). Such an outcome 
is doubly beneficial: The short-term processes almost never fall below 0 , and the time available to work on the long-term process without interruptions becomes predictable (or less variable). This rule is examined in $\S 4$.

For process 0 (long term) we specify an improvement target that takes the form of a rate,

$$
\liminf _{t \rightarrow \infty} \frac{L_{0}(t)}{t} \geq a_{0} .
$$

Equation (4) states that the long-term process must improve at least at the rate of $\alpha_{0}$. The manager is said to be successful if both Equations (3) and (4) are satisfied over a sufficiently long interval of time, and if the manager (when necessary) attends to at least one of the short-term processes that has fallen to or below 0 . Thermostat-type controls described in Radner (1976) are examples of the rules allowed by our definition. These rules are described in detail in $\S 4$. As we shall see, thermostat-type rules will suffice to achieve success when the parameters of the processes satisfy the conditions given in Theorem 1. For our analysis, we assume that the quantities, $\alpha_{0}, d_{i} \mathrm{~s}$, and $u_{i} \mathrm{~s}$ are greater than 0 .

We now turn to deriving the necessary and sufficient conditions for success. In Figure 1 we depict, for an illustration, a deterministic situation under which process $i$ is attended to during the first $N_{U}^{i}(t)$ units of time, and in this time interval its level increases at the rate of $u_{i}$. Thereafter, the process is left unattended for $N_{D}^{i}(t)$ units of time, during which its level decreases at the rate of $d_{i}$.

\section{Figure 1 A Deterministic Representation of Process Behavior with No Interrruptions}

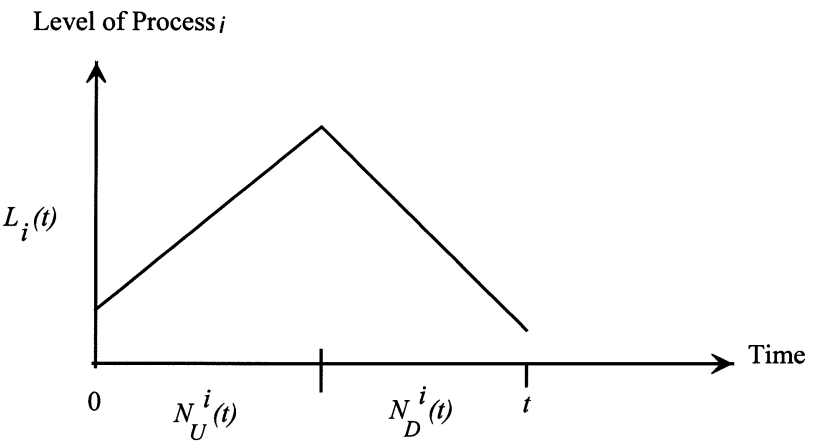

It follows from this figure that process $i$ will remain stable, and its level will not grow with time, if and only if the decrease in level $N_{D}^{i}(t) d_{i}$ is equal to the increase in level $N_{U}^{i}(t) u_{i}$. This condition can be formally stated as

$$
N_{D}^{i}(t) d_{i}=N_{U}^{i}(t) u_{i}+o(t),
$$

where the quantity $o(t)$ represents by convention a function that grows slower than $t$. By an application of the strong law of large numbers, it can be shown that the condition for stability given in Equation (5) will continue to hold for the stochastic model. Adding $N_{U}^{i}(t) d_{i}$ to both sides of Equation (5) we obtain,

$$
\left(N_{D}^{i}(t)+N_{U}^{i}(t)\right) d_{i}=N_{U}^{i}(t)\left(u_{i}+d_{i}\right)+o(t) .
$$

Equations (2) and (6) imply

$$
t d_{i}=N_{U}^{i}(t)\left(u_{i}+d_{i}\right)+o(t) .
$$

Or equivalently,

$$
\lim _{t \rightarrow \infty} \frac{N_{U}^{i}(t)}{t}=\frac{d_{i}}{\left(u_{i}+d_{i}\right)} .
$$

We summarize this result in Lemma 1.

Lemma 1. To achieve stability with regard to the shortterm processes, the fraction of time that the manager devotes to process $i$ should, on average, be equal to $d_{i} /\left(u_{i}+\right.$ $\left.d_{i}\right), i=1,2,3, \ldots, n$.

Lemma 1 provides the basis for establishing the conditions that are necessary as well as sufficient to guarantee success, as stated in Theorem 1.

THEOREM 1. The long-term goal can be achieved along with stability of the short-term processes if and only if

$$
1-\sum_{i=1}^{n} \frac{d_{i}}{u_{i}+d_{i}} \geq \frac{d_{0}+a_{0}}{\left(u_{0}+d_{0}\right)} .
$$

Proof. See appendix available at $\langle$ www.stern.nyu. edu/ zshapira/attention $\rangle$.

Equation (9) has an intuitive appeal. It states that the fraction of time available to the manager after attending to all maintenance (short-term activities) should be at least equal to the fraction of time necessary to prevent the deterioration of the long-term process and the fraction needed to improve it at the rate 
$a_{0}$. Theorem 1 is a special case of the results in Radner (1976), Radner and Rothschild (1975), and Rothschild (1975). However, our proof technique is different. In our model, instead of allowing the processes to jump up or down by at most one unit at a time, we could allow the jumps to be random but restricted to integer values and finite in expectation. In that case we should view the $u_{i} \mathrm{~s}$ and $d_{i} \mathrm{~s}$ as average improvement and deterioration rates, respectively. Theorem 1 can be shown to hold for this case as well; see, for example, Radner and Rothschild (1975).

\section{When Interruptions Are Costly}

In this section, we extend the model to the case when interruptions are costly. We model the cost of interruptions using two assumptions. The first assumption is that an interruption affects only the "level" of the long-term process, while the levels of short-term processes are unaffected due to interruptions. The second assumption is that the level of the long-term process, that is process 0 , drops by a fixed amount denoted as $\Delta$ upon interruption. This drop in the level due to an interruption should be interpreted as a set up cost, that is, upon being interrupted the manager has to increase the level of the long-term process by $\Delta$ to simply recover the original thinking position.

We illustrate the behavior of the short- and longterm processes in this model when the manager uses a rule that mimics the behavior of thermostats. To implement such a rule, the manager associates two levels, $B_{i}$ and $A_{i}$, where $B_{i}>A_{i}$ with each process $i$. The level $A_{i}$ is called the lower threshold level. When the level of process $i$ reaches this level, it signals that the process is not performing satisfactorily. The level $B_{i}$ is called the upper threshold level. This level is chosen by the manager to indicate satisfaction with the process. Define

$$
H_{i}=B_{i}-A_{i} .
$$

Consider the case when there is only one shortterm process and one long-term process. The behavior of the long- and short-term processes is shown in Figure 2.

Define the following quantities based on Figure 2:

Average time required for process 1 to raise from $A_{1}$ to $B_{1}=H_{1} / u_{1}$.

\section{Figure 2 The Effect of Interruption}

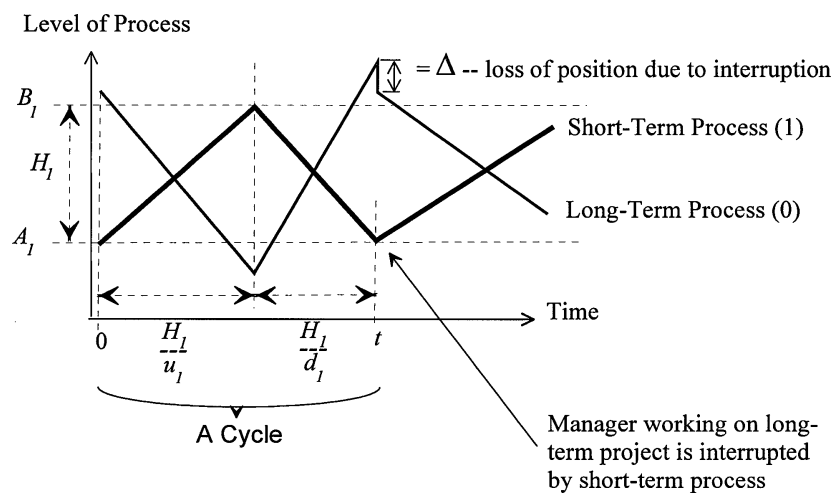

Average time for process 1 to drop from Level $B_{1}$ to $A_{1}=H_{1} / d_{1}$.

Define a cycle as the period during which the shortterm process is attended to, followed by the period during which the long-term process is attended to. The expected length of a cycle is given by $\left(H_{1} / u_{1}+\right.$ $\left.H_{1} / d_{1}\right)$. There is one interruption per cycle. Therefore,

$$
\begin{aligned}
\text { Average rate of interruptions } & =\frac{1}{\left(H_{1} / u_{1}+H_{1} / d_{1}\right)} \\
& =\frac{u_{1} d_{1}}{H_{1}\left(u_{1}+d_{1}\right)} .
\end{aligned}
$$

The interruptions introduce an additional downward drift to the long-term process. The additional drift due to the interruptions equals

(drop due to interruption) $\times$ (rate of interruptions)

$$
=\Delta \times \frac{u_{1} d_{1}}{H_{1}\left(u_{1}+d_{1}\right)} .
$$

Therefore, it is possible to achieve the long-term growth rate, if in a model in which there are no interruptions, it is possible to improve the long-term process at a rate greater than or equal to

$$
\left(a_{0}+\frac{\Delta u_{1} d_{1}}{H_{1}\left(u_{1}+d_{1}\right)}\right) .
$$

From Equations (9) and (11), it follows that the stability of the short-term process and long-term goal achievement are guaranteed if

$$
1-\frac{d_{1}}{\left(u_{1}+d_{1}\right)} \geq \frac{d_{0}+a_{0}+\frac{\Delta u_{1} d_{1}}{H_{1}\left(u_{1}+d_{1}\right)}}{u_{0}+d_{0}} .
$$


Equation (11) implies that with the smaller the value of $H_{1}$, and/or larger the value of $\Delta$, it becomes more difficult to achieve stability and long-term growth simultaneously. The formula in Equation (12) also suggests that the effect of interruptions can be mitigated by an appropriate choice of $H_{1}$. The result for the case in which there are several short-term processes is stated as Theorem 2. Denote the average duration of a busy period that the manager works uninterrupted on the long-term process as $T^{(0)}$.

THeOREM 2. When interruptions are costly, the longterm goal can be achieved, while simultaneously guaranteeing the stability of the short-term processes if and only if

$$
\begin{aligned}
T^{(0)} \geq \Delta / & \left(u_{0}+d_{0}-\left(a_{0}+d_{0}\right)\right. \\
& \left./\left(\left(u_{0}+d_{0}\right)\left(1-\sum_{i=1}^{n} \frac{d_{i}}{u_{i}+d_{i}}\right)\right)\right) .
\end{aligned}
$$

Proof. See the appendix available at $\langle$ www.stern. nyu.edu/ zshapira/attention $\rangle$.

The condition given in (13) also has intuitive appeal. Consider a cycle consisting of a busy period working on the development project and an idle period attending to maintenance activities. The term $\left(a_{0}+d_{0}\right) /\left(\left(u_{0}+d_{0}\right)\left(1-\sum_{i=1}^{n}\left(d_{i} /\left(u_{i}+d_{i}\right)\right)\right)\right)$ represents the fraction of the cycle that must be devoted to prevent the deterioration of the long-term process and improve it at the rate $\alpha_{0}$; see (9). Thus, the rest of the time during a cycle is available to recover from the cost of an interruption. This should indeed be greater than or equal to the fraction of time necessary to recover from an interruption, namely $\Delta / T^{(0)}\left(u_{0}+d_{0}\right)$, because $T^{(0)}\left(u_{0}+d_{0}\right)$ is the average length of a cycle and $\Delta$ is the cost of an interruption. We also should point out that the expression on the right-hand side of (13) does not depend on the rule but only on the parameters of the problem. The length of the busy period is, however, a consequence of the rule adopted by the manager. Thus, the manager has a target to achieve in attempting to obtain sufficiently long spells, during which he can work uninterrupted on the long-term process.

Several observations can be made based on Theorem 2. Unlike the case when interruptions are costless, the manager has to be more careful in choosing a rule for attending to the short-term processes. The difficulty in choosing a rule is due to the fact that the exact relationship between the choice of a rule and the value of $T^{(0)}$ is neither immediately evident nor intuitively obvious. A second and possibly equally serious (and not readily obvious) consequence is the downside impact of choosing large values of the threshold levels $\left(A_{i}\right.$ and $\left.B_{i}\right)$. Large values of the threshold levels increase the variance of the time available to the manager to work on a long-term project. For example, when there is only one shortterm process, the average length of the busy period working on the long-term project, $T^{(0)}$, equals $H_{1} / d_{1}$. The variance of this busy period equals $\left(H_{1}\left(1-d_{1}\right)\right) / d_{1}^{2}$ (see Feller (1968)) and grows linearly with $H_{1}$. This suggests that while stability can be achieved by increasing the value of $H_{1}$, the uninterrupted spells available for the manager to work on the long-term project might become more variable as a consequence.

As another example, consider the case when there is only one short-term process. Assume that when unattended the evolution of this process resembles a Brownian Motion (BM) with a negative drift equal to $d_{1}$ and standard deviation $\sigma_{d_{1}}$. When attended to, this process resembles a BM with positive drift of $u_{1}$ and standard deviation of $\sigma_{u_{1}}$. Call this the BM model. Assume that in this model the manager uses the strategy of thermostat control. It is known that the average time for a BM with drift $d_{1}$ to hit the level $H_{1}$ starting from level 0 is given by $H_{1} / d_{1}$; see Karlin and Taylor (1981). In this case, Condition (13) translates into

$$
1-\frac{d_{1}}{u_{1}+d_{1}} \geq \frac{d_{0}+a_{0}+\Delta\left(1-\frac{d_{1}}{u_{1}+d_{1}}\right) d_{1} / H_{1}}{u_{0}+d_{0}} .
$$

The variance of the busy period working uninterrupted on the long-term process is given by $H_{1} \sigma_{d_{1}}^{2} / d_{1}^{3}$, which again grows linearly with $H_{1}$. The variance is computed using the Laplace Stieljes transform of the time, $t$, for a BM with parameters $d_{1}$ and $s_{d_{1}}$ to hit the level $H_{1}$ starting from level 0. The LST, $E\left(e^{-s \tau}\right)=$ $e^{H_{1}\left(d_{1} / \sigma_{d_{1}}^{2}-\sqrt{d_{1}^{2}+2 s \sigma_{d_{1}}^{2}} / \sigma_{d_{1}}^{2}\right)}$; see Karlin and Taylor (1981).

As a third consequence, we observe that when the number of short-term processes increases, it might become intrinsically impossible to achieve stability 
using thermostat-type rules. To see this, assume that there are $n$ short-term processes, each of whose behavior follows the BM model. Assume that the manager uses a thermostat-type control, in which all short-term processes are driven to their respective upper-threshold levels before attending to the longterm process. Then upper and lower bounds for $T^{(0)}$ can be determined as follows:

$$
\sum_{i=1}^{n} H_{i} / \sum_{i=1}^{n} d_{i} \geq \min _{i}\left(H_{i} / d_{i}\right) \geq T^{(0)} \geq \min _{i}\left(H_{i}\right) / \sum_{i=1}^{n} d_{i} .
$$

The first inequality in this expression can be obtained by some algebraic manipulation. The second inequality follows from the fact that the minimum of hitting times will be less than the other individual hitting times and, therefore, will also be smaller in expectation. The second inequality needs some explanation. Assume that the manager is attending to the long-term process. During this time, whenever a short-term process deteriorates, assume that all other short-term processes deteriorate as well. Clearly the smallest value of $H_{i}$ will be hit first. The average hitting time will equal $\min _{i}\left(H_{i}\right) / \sum_{i=1}^{n} d_{i}$. Therefore, a sufficient condition for stability and achievement of the target rate of improvement with regard to the long term is given by

$$
\begin{aligned}
1-\sum_{i=1}^{n} \frac{d_{i}}{u_{i}+d_{i}} \geq & \left(a_{0}+d_{0}+\Delta \frac{\left(1-\sum_{i=1}^{n} \frac{d_{i}}{u_{i}+d_{i}}\right)\left(\sum_{i=1}^{n} d_{i}\right)}{\min _{i}\left(H_{i}\right)}\right) \\
& /\left(u_{0}+d_{0}\right) .
\end{aligned}
$$

This formula shows that to achieve stability, the minimum value of $H_{i}$ must increase along with the sum of $d_{i}$ s. This suggests that when there are many short-term processes, it becomes difficult to achieve stability and long-term growth using thermostat-type controls. Rothschild (1975) extends the models given in Radner and Rothschild (1975) by considering a cost of switching attention between processes. He, however, does not make the distinction between longand short-term processes. He also, does not consider the dual objectives of stability and growth as we do. However, he proves that the "simple" rule of putting out fires, suggested in Radner and Rothschild (1975), might prove inadequate toward meeting either of the criterion for survival as defined in $\S 2$. In that case, he goes on to show that the manager must contrive to work for longer spells at a time on each process than when using the putting out fires rule. This finding corresponds to our criterion (13) that the average busy period must be sufficiently long. Rothschild does not analyze the consequence of this on the variance of the busy period.

\section{Comparison of Rules of Attention Allocation}

It is of interest to compare how different rules perform with regard to the three criteria, namely, stability, long-term growth, and variance of the time available to attend to the long-term process. Unfortunately, analytical comparison of different rules is difficult because closed-form expressions for $T^{(0)}$ are hard to obtain, except in special cases. In this section, we describe a broad class of rules and compare the performance of rules with regard to the three criteria using virtual experiments. We focus primarily on the third criterion because, as shown earlier, if Condition (13) is satisfied, then there are rules that can be used to achieve stability as well as long-term growth. We also identify a rule (termed Continuous Improvement) that is nearly optimal in that it minimizes the variance of the time available to work on the long-term process.

\section{The Processes}

In the experimental set up (see Table 1) there are several short-term processes and one long-term process. Associated with each short-term process are the parameters $u$ and $d$. The manager chooses an upper and a lower threshold for short-term processes. The chosen lower threshold level may be different from 0 . To assess the efficacy of the rules, we vary both the number as well as the type of the short-term processes controlled by the manager (see Table 1 ). The number of short-term processes is 2,4 , and 8 in the first three virtual experiments. There are two types of shortterm processes: Type 1 processes are a little easier to improve than Type 2 processes and have higher priority compared to Type 2 processes. For example, Type 1 processes might be tasks that need routine approval, whereas Type 2 processes might require the manager to select among several alternatives. In the first three 
SESHADRI AND SHAPIRA

Managerial Allocation: The Effects of Interruptions

Table 1 Virtual Experiment Environments

\begin{tabular}{|c|c|c|c|}
\hline Experiment & $\begin{array}{l}\text { Number of Type } 1 \\
\text { Processes }^{\mathrm{a}}\end{array}$ & $\begin{array}{l}\text { Number of Type } 2 \\
\text { Processes }^{\mathrm{a}}\end{array}$ & $\begin{array}{c}\text { Theoretical Fraction of Time Available } \\
\text { to Work on Long-Term Process }{ }^{b}\end{array}$ \\
\hline \multirow[t]{3}{*}{1} & 1 & 1 & 0.808 \\
\hline & $u=0.25$ & $u=0.15$ & \\
\hline & $d=0.02$ & $d=0.02$ & \\
\hline \multirow[t]{3}{*}{2} & 2 & 2 & 0.617 \\
\hline & $u=0.25$ & $u=0.15$ & \\
\hline & $d=0.02$ & $d=0.02$ & \\
\hline \multirow[t]{3}{*}{3} & 4 & 4 & 0.233 \\
\hline & $u=0.25$ & $u=0.15$ & \\
\hline & $d=0.02$ & $d=0.02$ & \\
\hline \multirow[t]{3}{*}{4} & 5 & 1 & 0.512 \\
\hline & $u=0.25$ & $u=0.15$ & \\
\hline & $d=0.02$ & $d=0.02$ & \\
\hline \multirow[t]{3}{*}{5} & 1 & 5 & 0.044 \\
\hline & $u=0.25$ & $u=0.15$ & \\
\hline & $d=0.02$ & $d=0.03$ & \\
\hline
\end{tabular}

Note. ${ }^{a}$ Type 1 and Type 2 processes are both short-term processes. The total number of short-term processes is 2, 4, and 8 in the first three experiments and six in the fourth and fifth experiments. ${ }^{\mathrm{b}}$ The fraction of time available is used to not only work on the long-term project but also to recover the lost position due to interruptions. ${ }^{~}$ Each experiment was run 400 times for each of the 12 rules.

experiments there is a balanced number of short-term processes of each type, whereas in the last two we consider extreme situations in which there is only one of Type 1, and all the rest are of Type 2 or viceversa. Processes of the same type have the same process parameters and are assigned the same threshold values. From Equation (9), given the parameters of the short-term processes, we can compute the average fraction of time available to attend to the long-term project as well as to recover the lost position in the costly environment. This fraction is shown in the last column of Table 1.

In the description of the rules a short-term process is said to require attention when the level of the short-term process falls below the lower threshold level. To simplify breaking ties, short-term processes are numbered sequentially, and processes that have a lower index have higher priority.

\section{Rules for Attention Allocation}

Consider the manager's problem when attending to interruptions. The manager not only has to decide to which interruption(s) he should attend, but also when to return to the long-term project. For example, should the manager return to the long-term project only when all short-term processes are at their upper threshold level? Or, should the manager decide that the processes are under control when their threshold levels are above the lower threshold level? When the manager focuses attention on the upper threshold level, we label the rule as $\mathrm{HI}$, and when the focus is on the lower threshold level, we label the rule as LO. The focus of attention on one of these is reminiscent of the process described in March and Shapira (1992).

The second decision the manager has to make is whether she can interrupt a short-term job when another short-term process requires attention. When a short-term job can be interrupted, the rule followed by the manager is said to allow preemption, denoted as PREMP, and when preemption is not allowed, the rule is labeled NONPREMP. (Whether preemption is allowed or not is integral to the basic classification scheme of scheduling problems; see Pinedo 1995.) We have already specified that the manager is not 
allowed to idle when there are short-term processes that require attention-therefore, the rules we consider are said to be nonidling.

The third decision that the manager has to make is to determine which of the waiting jobs will be attended to next. As described by Levitt et al. (1994), some of the common rules followed by managers are preassigned priority (PRIORITY), the first-in-firstout (FIFO) rule, the last-in-first-out rule (LIFO), and randomly-selected job to process (RANDOM). Most other rules described in the scheduling literature (cf. Pinedo 1995) either use the processing time of jobs or the due date of jobs to set priorities, but these methods are not applicable in the present context. Thus, the class of rules described below is a rather comprehensive collection of scheduling rules. What is unique and new about this collection is the idea that the focus of attention determines when the manager returns to work on the long-term project. We consider the following 12 rules:

HI PREMP PRIORITY. The manager begins work on short-term processes whenever a short-term process requires attention. All short-term processes are preassigned a level of priority. Once the manager has switched attention to short-term processes, she attends to the short-term process that has the highest priority and works on it for one unit of time. At the end of the one unit of time, the manager scans all short-term processes (and unless some short-term process is below the critical threshold level of 0 ) and chooses the short-term process to work on in the next unit of time that is of the highest priority and whose level is below the upper threshold level (thus, the focus is $\mathrm{HI}$ ). The manager returns to the long-term project only when all short-term processes are at their upper threshold level.

HI NONPREMP PRIORITY. This rule is identical to the previous rule, except that once the manager chooses to attend to a short-term process, she raises its level to its upper threshold level before choosing the next process to attend to.

HI NONPREMP FIFO. This rule is identical to the previous rule, except that after raising the level of a short-term process to its upper threshold level the manager attends next to the short term process that was the first to fall below its upper threshold level.

HI NONPREMP LIFO. This rule is identical to the previous rule, except that the next short-term process the manager attends to is the one that was the last to fall below its upper threshold level.

HI NONPREMP RANDOM. This rule is identical to the previous rule, except that the manager randomly chooses the next short-term process among processes that are below their upper threshold levels.

HI Partial PREMP PRIORITY. This rule is a hybrid rule that combines HI PREMP PRIORITY and HI NONPREMP PRIORITY. Short-term processes that have higher priority, compared to the process currently attended to, can preempt the current process if one of their levels falls below the upper threshold level (thus, the focus is HI). Once the manager finishes raising the level of a short-term process to its upper threshold level, the manager scans short-term processes of lower priority that are below their upper threshold level (as focus is HI) and attends to the process that has the highest priority.

\section{Rules with Focus on Low}

Corresponding to each of last five rules, we define five more rules by changing the focus to LO. For example, the LO NONPREMP PRIORITY Rule is similar to the HI NONPREMP PRIORITY Rule, except that after raising the level of a short-term process to its upper threshold level the manager chooses the shortterm process to work on in the next unit of time that is of the highest priority and whose level is below the lower threshold level. In this fashion, we define the rules LO NONPREMP FIFO, LO NONPREMP LIFO, LO NONPREMP RANDOM, and LO Partial PREMP PRIORITY.

CONTINUOUS IMPROVEMENT (CI). This rule is a modified version of the "putting out fires" rule described in Radner (1976) and Radner and Rothschild (1975). In the continuous improvement tradition, the manager sets a target of slowly improving the short-term processes. The rate of increase is 
chosen to be $K \log (t)$, where $K$ is an arbitrary positive constant. The rationale for choosing $K \log (t)$ as the rate of increase is that $\log (t) / t$ goes to 0 as $t$ goes to $\infty$. Therefore, the effort put forth in obtaining this rate of growth does not take away from the time necessary to maintain the stability of the shortterm processes. The manager also chooses an interval of time $T$, during which she plans to work only on the long-term process, unless interrupted by a shortterm process requiring attention. Either at the end of the interval or when interrupted, the manager surveys all the short-term processes. If necessary, the manager attends to the short-term process that is the farthest away from its targeted rate of improvement of $K \log (t)$. She returns to work on the long-term process for a duration of $T$ when all short-term processes are above their target level of improvement.

The rules that focus on $\mathrm{HI}$ are conservative in outlook. The rules that focus on LO are less conservative and could be said to be satisficing. The CI rule mimics continuous improvement (Ohno 1988). When CI is used, the levels of all the short-term processes are slowly but almost surely increasing due to continuous improvement, thus the variance of the periods during which the manager attends to the long-term process asymptotically goes to 0 .

\section{Virtual Experiments}

Each virtual experiment comprises choosing an environment from Table 1, a target value of the average busy period (the average time the manager attends to the long-term project uninterrupted), and a rule. It is important to emphasize that the average time that the manager attends to the long-term process uninterrupted governs the rate at which the level of the long-term process increases, see (13) and (A17) in the online appendix. Thus, to compare rules it is necessary to maintain this quantity at a target value to compare the performance of the rules. Each virtual experiment is simulated for 103,000 units of time. Each experiment is replicated 400 times. We show the summary results in Table 2.

It follows from Theorem 2 that the average fraction of time that is devoted to the long-term process is independent of the attention allocation rule used by the manager, as long as the short-term processes are stable. This is evident from the values displayed in the last column of Table 2 (also, compare with the theoretical prediction shown in the last column of Table 1). Examination of the variance of the busy period reveals that the Continuous Improvement $(\mathrm{CI})$ rule results in the smallest variance $(p<0.001)$, as expected. The surprising finding is that rules with $\mathrm{HI}$ as focus outperform rules with LO as focus ( $p<$ 0.001). Given that the focus is either HI or LO, except in three cases (two cases in Experiment 2: HI focus and one case in Experiment 5: HI focus) the FIFO rule does better than the rules that allow preemption $(p<0.1)$.

Comparing the first three experiments, we see that the increase in variance under rules that use LO as focus when compared to rules that focus on $\mathrm{HI}$ gets more pronounced when the number of shortterm processes increases. The ratio of variance (LO focus to $\mathrm{HI}$ focus) is approximately proportional to the square of the number of short-term processes. The results from the last two experiments confirm that the findings from the balanced cases are indeed general. Moreover, in Experiment (5), the manager has very little time to devote to the long-term process. Consequently, the variance of the busy period for rules that use LO as focus is enormous. The CI rule gives remarkable performance in Experiment (5) when compared to other rules, confirming the robustness of this rule. The CI rule clearly outperforms the other rules by allowing the manager to take planned breaks of fixed duration to work on the long-term process. Indeed, when the manager uses this, he "survives" and "eventually succeeds" if the criterion in (13) is met. It is also not surprising that the variance of the busy period eventually goes to 0 , indicating that the CI rule (or several possible clones of this rule) is nearly optimal with regard to meeting the three criteria for success.

\section{Discussion}

In looking over the results, an intuitive justification could be made for using a rule that has $\mathrm{HI}$ as focus over rules that have LO as focus. When employing a $\mathrm{HI}$ focus, the manager raises all the processes to their respective upper threshold levels. Using LO as 
SESHADRI AND SHAPIRA

Managerial Allocation: The Effects of Interruptions

Table 2 Comparison of Rules

\begin{tabular}{|c|c|c|c|c|c|c|}
\hline \multirow[b]{2}{*}{ Environment } & \multirow[b]{2}{*}{ Rule } & \multicolumn{4}{|c|}{ Length of Busy Period } & \multirow[b]{2}{*}{$\%$ of Time Working on Long-Term Process } \\
\hline & & Average & SE & Variance & SE & \\
\hline \multirow[t]{12}{*}{1} & HI PREMP PRIORITY & 315.6 & 6.7 & 11239.3 & 47.5 & 80.6 \\
\hline & HI NONPREMP PRIORITY & 315.4 & 6.8 & 11061.9 & 46.9 & 80.5 \\
\hline & HI NONPREMP FIFO & 315.6 & 6.8 & 11059.5 & 47.7 & 80.5 \\
\hline & HI NONPREMP LIFO & 315.6 & 6.8 & 11059.5 & 47.7 & 80.5 \\
\hline & HI NONPREMP RANDOM & 314.7 & 7.3 & 11136.9 & 56.0 & 80.5 \\
\hline & HI Partial PREMP PRIORITY & 315.6 & 6.7 & 11239.3 & 47.5 & 80.6 \\
\hline & CONTINUOUS IMPROVEMENT & 315.9 & 0.5 & 314.3 & 7.9 & 80.1 \\
\hline & LO NONPREMP PRIORITY & 314.3 & 8.4 & 27598.7 & 98.6 & 80.6 \\
\hline & LO NONPREMP FIFO & 316.0 & 8.8 & 27213.7 & 105.1 & 80.6 \\
\hline & LO NONPREMP LIFO & 316.0 & 8.8 & 27213.7 & 105.1 & 80.6 \\
\hline & LO NONPREMP RANDOM & 314.6 & 9.6 & 26983.8 & 109.1 & 80.4 \\
\hline & LO Partial PREMP PRIORITY & 318.0 & 7.8 & 27936.8 & 119.5 & 80.5 \\
\hline \multirow[t]{12}{*}{2} & HI PREMP PRIORITY & 289.8 & 5.2 & 6499.9 & 32.4 & 60.9 \\
\hline & HI NONPREMP PRIORITY & 289.3 & 5.4 & 6514.8 & 32.0 & 60.9 \\
\hline & HI NONPREMP FIFO & 289.1 & 5.5 & 6479.6 & 34.5 & 60.8 \\
\hline & HI NONPREMP LIFO & 289.3 & 4.8 & 6443.4 & 33.1 & 60.9 \\
\hline & HI NONPREMP RANDOM & 290.2 & 5.6 & 6497.2 & 36.1 & 60.9 \\
\hline & HI Partial PREMP PRIORITY & 289.8 & 5.2 & 6499.9 & 32.4 & 60.9 \\
\hline & CONTINUOUS IMPROVEMENT & 289.0 & 0.6 & 254.6 & 9.4 & 59.9 \\
\hline & LO NONPREMP PRIORITY & 286.5 & 10.9 & 42356.9 & 200.3 & 61.0 \\
\hline & LO NONPREMP FIFO & 292.5 & 12.6 & 42124.5 & 199.3 & 61.0 \\
\hline & LO NONPREMP LIFO & 291.5 & 10.8 & 42625.9 & 191.1 & 61.0 \\
\hline & LO NONPREMP RANDOM & 292.4 & 11.4 & 42468.5 & 206.2 & 61.1 \\
\hline & LO Partial PREMP PRIORITY & 290.0 & 10.0 & 44643.8 & 208.7 & 61.0 \\
\hline \multirow[t]{12}{*}{3} & HI PREMP PRIORITY & 246.2 & 6.5 & 3696.9 & 30.3 & 21.8 \\
\hline & HI NONPREMP PRIORITY & 246.0 & 6.3 & 3674.5 & 29.6 & 21.8 \\
\hline & HI NONPREMP FIFO & 245.7 & 6.5 & 3648.9 & 30.2 & 21.8 \\
\hline & HI NONPREMP LIFO & 246.1 & 6.1 & 3665.5 & 28.0 & 21.8 \\
\hline & HI NONPREMP RANDOM & 245.7 & 6.3 & 3654.4 & 28.8 & 21.8 \\
\hline & HI Partial PREMP PRIORITY & 246.2 & 6.5 & 3696.9 & 30.3 & 21.8 \\
\hline & CONTINUOUS IMPROVEMENT & 246.0 & 1.3 & 198.6 & 15.7 & 19.9 \\
\hline & LO NONPREMP PRIORITY & 249.3 & 18.0 & 56090.4 & 424.9 & 22.7 \\
\hline & LO NONPREMP FIFO & 254.3 & 19.5 & 55753.2 & 423.4 & 22.6 \\
\hline & LO NONPREMP LIFO & 253.3 & 18.2 & 55332.7 & 423.9 & 22.6 \\
\hline & LO NONPREMP RANDOM & 253.8 & 18.5 & 55372.9 & 431.2 & 22.7 \\
\hline & LO Partial PREMP PRIORITY & 246.9 & 17.5 & 58786.1 & 451.5 & 22.7 \\
\hline \multirow[t]{5}{*}{4} & HI PREMP PRIORITY & 330.4 & 7.0 & 9409.8 & 52.0 & 52.3 \\
\hline & HI NONPREMP PRIORITY & 328.6 & 7.1 & 9222.9 & 51.6 & 52.3 \\
\hline & HI NONPREMP FIFO & 328.5 & 7.2 & 9152.6 & 51.2 & 52.3 \\
\hline & HI NONPREMP LIFO & 328.4 & 7.1 & 9254.7 & 51.5 & 52.3 \\
\hline & HI NONPREMP RANDOM & 328.6 & 6.9 & 9219.8 & 52.9 & 52.3 \\
\hline
\end{tabular}


SESHADRI AND SHAPIRA

Managerial Allocation: The Effects of Interruptions

Table 2 Continued

\begin{tabular}{|c|c|c|c|c|c|c|}
\hline \multirow[b]{2}{*}{ Environment } & \multirow[b]{2}{*}{ Rule } & \multicolumn{4}{|c|}{ Length of Busy Period } & \multirow[b]{2}{*}{$\%$ of Time Working on Long-Term Process } \\
\hline & & Average & SE & Variance & SE & \\
\hline \multirow{19}{*}{5} & HI Partial PREMP PRIORITY & 330.4 & 7.0 & 9409.8 & 52.0 & 52.3 \\
\hline & CONTINUOUS IMPROVEMENT & 329.7 & 0.9 & 359.4 & 15.7 & 50.7 \\
\hline & LO NONPREMP PRIORITY & 328.9 & 14.8 & 84032.8 & 499.7 & 52.7 \\
\hline & LO NONPREMP FIFO & 334.5 & 15.0 & 79954.6 & 461.0 & 52.6 \\
\hline & LO NONPREMP LIFO & 334.6 & 15.8 & 80241.0 & 481.4 & 52.7 \\
\hline & LO NONPREMP RANDOM & 333.4 & 16.0 & 79551.9 & 461.3 & 52.6 \\
\hline & LO Partial PREMP PRIORITY & 328.9 & 14.6 & 85499.4 & 545.7 & 52.7 \\
\hline & HI PREMP PRIORITY & 226.3 & 20.4 & 2380.0 & 68.0 & 4.2 \\
\hline & HI NONPREMP PRIORITY & 227.2 & 19.2 & 2414.2 & 74.3 & 4.2 \\
\hline & HI NONPREMP FIFO & 226.5 & 18.9 & 2461.9 & 70.5 & 4.3 \\
\hline & HI NONPREMP LIFO & 226.6 & 18.7 & 2438.3 & 66.3 & 4.2 \\
\hline & HI NONPREMP RANDOM & 228.4 & 19.3 & 2326.7 & 63.6 & 4.3 \\
\hline & HI Partial PREMP PRIORITY & 226.3 & 20.4 & 2380.0 & 68.0 & 4.2 \\
\hline & CONTINUOUS IMPROVEMENT & 226.7 & 2.5 & 51.9 & 24.9 & 3.4 \\
\hline & LO NONPREMP PRIORITY & 230.9 & 139.1 & 117099.0 & 3692.0 & 4.4 \\
\hline & LO NONPREMP FIFO & 223.8 & 143.9 & 101555.4 & 3081.7 & 4.4 \\
\hline & LO NONPREMP LIFO & 223.2 & 154.3 & 97616.9 & 2658.8 & 4.3 \\
\hline & LO NONPREMP RANDOM & 229.6 & 141.0 & 103760.2 & 2683.1 & 4.4 \\
\hline & LO Partial PREMP PRIORITY & 221.2 & 130.2 & 119476.0 & 3329.8 & 4.6 \\
\hline
\end{tabular}

the focus, she is satisfied if none of the short-term processes is at the lower threshold level and the one she attended to is at its upper threshold level. As a consequence, two things can happen: Either the manager is fortunate and does not suffer an interruption for a long while, or if some short-term process is close to its lower threshold level, the manager is interrupted almost immediately. Rules that have $\mathrm{HI}$ as focus are not only conservative but might also represent the behavior of a manager who pays attention to detail. The CI rule, on the other hand, could represent the behavior of a manager who takes planned breaks from development activity to improve the processes that are likely to affect her performance. Helgesen's (1990) work suggests that such behavior is not uncommon. This is in contrast to Mintzberg's managers, who are said to work at unrelenting pace, have interrupted and fragmented days, and lacked time for reflection. Helgesen studied managers who maintained a steady pace, took small breaks, and incorporated interruptions as part of the flow of work days. This pattern is in line with the CI rule if in addition the manager attempts to improve the short-term processes during the breaks from working on the long-term project. The CI rule is also reminiscent of the practice of taking planned breaks to discuss problems in quality circles. Thus, the numerical results illustrate the essence of the theme that rule selection in the costly environment should be targeted toward either eliminating interruptions or toward having planned interruptions, rather than upon satisficing. Our experiments assume that the set of processes controlled by a manager is invariant over time. Even if it were not so, the conclusions that are presented will not change. We have experimented with environments in which short-term processes are added, or their parameters changed during the experiment and obtained virtually similar results.

It should be noted that the ways managers allocate their time and effort is also embedded in the particular organizational context in which they operate. The interruptions we dicuss are of the type of phone calls 
a manager gets from his superiors, from important clients, or from subordinates who have an important problem that prevents them from completing their tasks. We did not attempt to describe the scheduling problem of a person who has complete control of his agenda, although the models can work in this case as well. Clearly, organizational culture and incentive systems play an important role in how managers allocate their attention (Shapira 1995). In particular, organizations may have different degrees of tolerance for the levels that important processes are set at and are allowed to vary. Some organizations insist that all processes should consistently be at their upper thresholds, while other organizations may be tolerant if the level of processes is between their lower and upper thresholds. In addition, various tasks may allow different degrees of freedom in changing the levels of key processes and, hence, they affect the rules that can be used.

We would like also to emphasize two more aspects of the rules that we have compared, namely, the frequency with which short-term processes went critical (hit or went below level 0) and the issue of being focused when working on projects that are critical to an enterprise. First, we have assumed that the lower threshold levels are sufficiently greater than 0 , so there are few interruptions of a critical nature. This in itself could be difficult to achieve in practice if an initial effort is not made to put things in order before embarking on a long-term project. The consequence of short-term processes becoming critical could become even greater than the loss of time and might include loss of money and personal discomfort. Second, it is an everyday experience that managers as well as academics attempt to set aside times during which they can work uninterrupted. The success in such an endeavor depends, based on our analysis, on the rule used to deal with interruptions. Such issues should be examined in future research.

We have outlined a model of managerial time and effort allocation given the constraints of time availability and the need to attend to multiple tasks. We started with the notion that interruptions pose no problem and continued with a model dealing with costly interruptions. Twelve rules were proposed to analyze managerial behavior under such conditions. We assume that managers want to devote as much time as possible to long-term projects such as those involved with $R \& D$. We further assume that in attempting to secure time for dealing with long-term projects, managers aspire to create stable periods of time in which they are not interrupted. Our analysis suggests that the satisficing mode that has long been seen as a good descriptive mode of the way managers work may not be a sufficient rule if both stability and growth are contemplated. Given the structure of the environment and the limitations on managerial attention spans, it appears that a model assuming sequential rather than parallel processing fares better in guiding managerial attention allocation when complex tasks are involved (cf. Simon 1992). Future research should look at the degree to which time sharing can affect the use of rules we discussed.

The renewed interest in the effect of interruptions on behavior in the psychology literature (cf. Sarason et al. 1996) may add more interesting facets to the study of managerial attention allocation under time and information-processing constraints. The implications for managing organizations suggest that focusing on rules governing managerial behavior and managerial attention allocation may enhance our understanding of managerial behavior. Employing mathematics to describe models of managerial behavior and using computer simulations to test their predictions (cf. Lin 1994, Pete et al. 1994) can facilitate research on such complex and important managerial domain.

\section{Acknowledgments}

The authors gratefully acknowledge comments by Vipul Agrawal, Roy Radner, Yosef Rinott, Matt Sobel, and Itzhak Venezia, as well as by participants in seminars at the Hebrew University, New York University, and Washington University.

\section{References}

Buzacott, J. A., J. G. Shanthikumar. 1993. Stochastic Models of Manufacturing Systems. Prentice Hall, Englewood Cliffs, NJ.

Cohen, J. W. 1969. The Single Server Queue. North-Holland Pub. Co., Amsterdam, The Netherlands.

Eisenhardt, K. M. 1989. Making fast strategic decisions in highvelocity environments. Acad. Management J. 32(3) 543-576. 
Feller, W. 1968. An Introduction to Probability Theory and Its Applications, 3rd ed. Willey, New York.

Ghez, G. R., G. S. Becker. 1975. The Allocation of Time and Goods Over the Life Cycle. Columbia University Press, New York.

Helgesen, S. 1990. The Female Advantage: Women's Ways of Leadership. Doubleday Currency, New York.

Karlin, S., H. M. Taylor. 1981. A Second Course in Stochastic Processes. Academic Press, New York.

Levitt, R. E., G. P. Cohen, J. C. Kunz, C. I. Nass, T. Christiansen, Y. Jin. 1994. The "virtual design team:" Simulating how organization structure and information processing tools affect team performance. K. M. Carley, M. J. Prietula, eds. Computational Organization Theory. Lawrence Erlbaum Associates, Hillsdale, NJ. 1-18.

Lin, Z. 1994. A theoretical evaluation of measures of organizational design: Interrelationship and performance predictability. K. M. Carley, M. J. Prietula, eds. Computational Organization Theory. Lawrence Erlbaum Associates, Hillsdale, NJ. 113-159.

_, K. Carley. 1997. Organizational decision making and error in a dynamic task environment. J. Math. Sociology. 22 125-149.

March, J. G. 1994. A Primer on Decision Making. Free Press, New York.

— H. A. Simon. 1993. Organizations, 2nd ed. Blackwell, Cambridge, MA.

_ Z. Shapira. 1987. Managerial perspectives on risk and risk taking. Management Sci. 33 1404-1418.

_ 1 1992. Variable risk preferences and the focus of attention. Psych. Rev. 99 172-183.

Maule, J., O. Svenson. 1993. Theoretical and empirical approaches to behavioral decision making and their relation to time constraints. J. Maule, O. Svenson, eds. Time Pressure and Stress in Human Judgment and Decision Making. Plenum, New York.

Mintzberg, H. 1973. The Nature of Managerial Work. Harper \& Row, New York.

Ohno, T. 1988. Toyota Seisan Hoshiki (Toyota Production System: Beyond Large-scale Production). Productivity Press, Cambridge, MA.
Perlow, L. 1999. The time famine: Toward a sociology of work time. Admin. Sci. Quart. 44 57-81.

Pete, A., K. R. Pattipati, D. L. Kleinman. 1994. Optimization of detection networks with multiple event structures. IEEE Trans. Automatic Control. 39(8) 1702-1707.

Pinedo. M. 1995. Scheduling: Theory, Algorithms and Systems. Prentice Hall, Englewood Cliffs, NJ.

Radner, R. 1975. A behavioral model of cost reduction. Bell J. Econom. Management Sci. 6(1) 196-215.

- B. Rothschild. 1975. On the allocation of effort. J. Econom. Theory. 10(3) 358-376.

Rothschild, M. 1975. Further notes on the allocation of effort. R. H. Day, T. Groves, eds. Adaptive Economic Models. Proc. Math. Res. Center. University of Wisconsin-Madison: Academic Press, New York.

Ross, S. M. 1983. Stochastic Processes. John Wiley \& Sons, New York. Sarason, I., G. Pierce, B. Sarason, eds. 1996. Cognitive Interference: Theories, Methods and Findings. Erlbaum, Mahwah, NJ.

Shapira, Z. 1995. Risk Taking: A Managerial Perspective. Russell Sage Foundation, New York.

Shwartz, A., A. Weiss. 1995. Large Deviations for Performance Analysis: Queues, Communications, and Computing. Chapman and Hall, London, U.K.

Simon, H. A. 1955. A behavioral model of rational choice. Quart. J. Econom. 69 99-118.

. 1967. Motivational and emotional controls of cognition. Psych. Rev. 74(1) 29-39.

_. 1987. Making management decisions: The role of intuition and emotion. Acad. Management Executive. 1 57-64.

- 1992. The bottleneck of attention: Connecting thought with motivation. W. D. Spalding, ed. Nebraska Sympos. Motivation. University of Nebraska Press, Lincoln, NE, 41.

Speier, C., J. Valacich, I. Vessey. 1999. The influence of task interruption on individual decision making: An information overload perspective. Decision Sci. 30 337-360.

Wright, P. 1974. The harasses decision maker: Time pressure, distractions and the role of evidence. J. Appl. Psych. 59 555-561.

Ye, M., K. Carley. 1995. Radar-soar: Toward an artificial organization composed of intelligent agents. J. Math. Sociology. 20 219-246.

Accepted by Linda Argote. This paper was with the authors 7 months for 2 revisions. 